\section{Prevalence of Anemia in Khulna, Bangladesh and Comparative Study among Available Hematinic Preparations}

\author{
*Yeakuty Marzan Jhanker ${ }^{1}$, Naz Hasan Huda ${ }^{2}$ and Riaz Uddin ${ }^{2}$ \\ ${ }^{1}$ Department of Pharmacy, The University of Asia Pacific \\ Dhaka-1209, Bangladesh. \\ ${ }^{2}$ Department of Pharmacy, Stamford University Bangladesh, \\ 51 Siddeswari Road, Dhaka-1217, Bangladesh.
}

*Corresponding Author

Yeakuty Marzan Jhanker

Lecturer, Department of Pharmacy

The University of Asia Pacific

Dhaka-1209, Bangladesh.

Contact no.: +8801746 487946

E-mail: jhanker2001@yahoo.com

Received - 03 November 2010

Accepted for Publication - 30 November 2010

\begin{abstract}
Among many disorders of blood, anemia is the most common. Undetected anemia with minor or vague symptoms occurs in many people, especially in the third world country (Xiong et al., 2003). Patients having a lower plasma hemoglobin concentration than normal are termed as anemic. This may results from decreased number of circulating red blood cells (RBC). Broadly, causes of anemia may be classified as impaired RBC production, increased RBC destruction, blood loss and fluid overload (Kaushansky and Kipps, 2006). The most common cause of anemia is blood loss, but this usually doesn't cause any lasting symptoms unless a relatively impaired RBC production develops, in turn most commonly by iron deficiency. Mild to moderate iron deficiency anemia is treated by oral iron supplementation with hematinic preparations - ferrous sulfate, ferrous fumarate, or ferrous gluconate (Glahn et al., 2000).
\end{abstract}

In this communication we report the prevalence of iron deficiency anemia among residents of Khulna, Bangladesh. A cross-sectional study was conducted in which a total of 200 in-patients were selected randomly from different hospitals and clinics of the city including 100 children (42 male and 58 female) and 100 adult females. Their disease record files were audited and analyzed to study the extent and treatment pattern of anemia. Patient hemoglobin concentration was taken as the indicator of anemia. All individuals participated in the study were informed about the objectives of the study and were assured with regards to confidentiality. A simple, self explanatory questionnaire was also developed and used for data collection.

From the collected data it was revealed that iron supplements are widely used for the treatment as well as prophylaxis of anemia. Iron absorption in the human body takes place in ferrous form much faster and in better quantity than ferric form. However, ferrous form present in the dosage forms can be easily oxidized to ferric form (Pitarresi et al., 2008). Therefore, a comparison was made among different brands of iron supplements available in local chemist shops. 12 brands of ferrous fumarate and 10 brands of ferrous sulphate preparations were compared by their physical properties like hardness, friability, weight variation, disintegration time, dissolution time etc. and also were chemically analyzed in the laboratory to determine their potency.

The results of the survey showed that a significant number of female and children of Khulna city is anemic. 104 disease records among the 200 randomly selected patients' record, were found to have hemoglobin test. Among them 23 adult females (23\%) and 21 children (21\%) were found to have lower hemoglobin concentration than normal. For the adult female patients, most commonly administered iron supplement were ferrous fumarate $(48 \%)$ and ferrous sulphate $(44 \%)$. In case of the anemic children, many of them (62\%) were suggested to increase their food iron supplement. Rest of them was prescribed with ferrous fumarate (14\%) and ferrous sulphate (24\%).

Packaging status of all the samples under investigation was satisfactory. All of them passed the BP specification in the physical tests. However, the potency test showed a shocking result. Only 5 out of 22 test samples complied with the BP specifications of potency for the ferrous fumarate tablets $(90-105 \%)$, for the ferrous fumarate capsules (95-105\%) and for the ferrous sulphate capsules (95-105\%). The following figure clearly interprets the findings: 




Figure 1: Comparison among the potencies of different brands of hematinic preparations.

An indirect correlation can be made between the prevalence of anemia with the quality in terms of potency of hematinic preparations from this study. Due to limited resource, manpower and economic support, the result indicates only regional information. To arrive at a valid conclusion of this type of study and to get a clear picture of the occurrence of anemia in Bangladesh as well as quality of hematinic products, more research should be carried out. The information of this communication can surely be taken as supporting data for future studies and can be consulted for occasional information.

\section{REFERENCES}

Xiong X, Buekens P, Fraser WD, Guo Z. (2003), Anemia during pregnancy in a Chinese population, International Journal of Gynecology \& Obstetrics. 83(2):159-164.

Kaushansky K and Kipps TJ (2006) In - Goodman \& Gilman's - The Pharmacological Basis of Therapeutics, $11^{\text {th }}$ Edition, McGraw-Hill Medical Publishing Division, Digital Edition, Chapter 53.

Glahn RP, Rassier M, Goldman MI, Lee OA, Cha J. (2000), A comparison of iron availability from commercial iron preparations using an in vitro digestion/caco-2 cell culture model. The Journal of Nutritional Biochemistry. 11(2):62-68.

Pitarresi G, Tripodo G, Cavallaro G, Palumbo FS, Giammona G. (2008), Inulin-iron complexes: A potential treatment of iron deficiency anaemia, European Journal of Pharmaceutics and Biopharmaceutics. 68(2):267-276. 